\title{
A FPCB Cutting Process using a Pico-second Laser
}

\author{
Dongsig Shin ${ }^{1}$, Jaehoon Lee ${ }^{1}$, Hyonkee Sohn ${ }^{1}$, Jiwhan Noh ${ }^{1}$ and Byoungman Paik ${ }^{1}$ \\ ${ }^{1}$ Korea Institute of Machinery \& Materials, 104 Sinseongno Yuseong-gu, Daejeon, 305-343, Korea \\ E-mail:dsshin@kimm.re.kr
}

\begin{abstract}
Laser micromachining has increasingly been applied to the electronics industry, where a strong demand exists for the precision machining of high-density, multi-layer, and multi-material components due to the ever-decreasing size of electronic products such as cellular phones, MP3 players, and digital cameras. At present, multi-layered flexible printed circuit boards (FPCBs) are being mechanically cut with a punching die. The mechanical cutting of FPCBs causes such defects as burrs on layer edges, cracks in terminals, delamination and the chipping of layers. Here, a pico-second laser (355 and $532 \mathrm{~nm}$ ) and a UV nano-second laser were used to cut FPCBs to examine the applicability of these types of lasers and to compare the cut quality when using them. In this study, the thermal effect and chemical change on flexible copper clad laminate (FCCL) were examined to solve problems related to surface debris and short-circuiting, which can occur as a result of a photothermal effect. The laser cutting of FCCL, which comprises the base material of a FPCB, was carried out while adjusting the variables of the peak power, scanning speed, wavelength and pulse duration. Points to which special attention should be paid include a fast scanning speed, a low repetition rate and a high peak power, al of which are required for precision machining.
\end{abstract}

DOI: 10.2961/jlmn.2010.01.0011

Keywords: FPCB (Flexible Printed Circuit Board), FCCL (Flexible Copper Clad Laminate), picosecond laser, nano-second laser, cutting

\section{Introduction}

The current development trend for electronic products can be characterized by light weight, slim shape and high portability. Traditional rigid circuit boards will be replaced by flexible printed circuits and rigid-flex circuits. In particular, modern mobile phones, PDAs and laptops have adopted various FPCBs (Flexible Printed Circuit Boards). These are small and lightweight and are thus significantly lower in price.

FPCBs are remarkably robust, as they are capable of being mechanically deformed frequently without degradation. Nonetheless, they present manufacturing challenges. Mechanical methods such as punching often lead to delamination of the FPCB and cracking of the terminal in the connector [1]. For these reasons, the industry is dedicated to finding a non-contact solution, such as laser cutting, to address this problem [2-4].

The laser cutting process is a clean, accurate, and convenient process for flexible materials such as a polymer in comparison with mechanical punching process. Moreover, this technique has the advantage in processing as there is no need for high-cost punching molds. However, some limitations exist, such as those associated with surface debris, electronic shorting and low productivity. In particular, electronic shorting, which originates from conductive particles and a photo-thermal effect [5-8], is the most serious defect associated with the laser cutting process of a FPCB.

Thus, we attempted to develop a simple laser cutting process that can eliminate carbon particles and lower the photo-thermal effect on a surface or cut edge of a FPCB [9, 10]. Further, we have subsequently collected further data on productivity and electronic shorting and wish to report on the detail of our investigation.

Table 1 Comparison between punching and laser cutting processes of a FPCB

\begin{tabular}{|c|c|c|}
\hline Process & Punching process & Laser cutting \\
\hline $\begin{array}{l}\text { Mass } \\
\text { produc- } \\
\text { tivity }\end{array}$ & $\begin{array}{c}\text { High } \\
(500-600 / \mathrm{hr})\end{array}$ & Low \\
\hline $\begin{array}{l}\text { Flexi- } \\
\text { bility }\end{array}$ & $\begin{array}{c}\text { Low } \\
(\text { design }>2 \text { days, }>10 k \$)\end{array}$ & $\begin{array}{c}\text { High } \\
\text { (design }<\text { several } \\
\text { hours) }\end{array}$ \\
\hline Process & $\begin{array}{l}\text { Two steps or several } \\
\text { steps }\end{array}$ & Single step \\
\hline $\begin{array}{l}\text { Limita- } \\
\text { tion }\end{array}$ & $\begin{array}{l}\text { - coarse cutting edge } \\
\text { - delamination of film } \\
\text { - crack of the terminal } \\
\text { - low accuracy } \\
\quad( \pm 0.1 \mathrm{~mm})\end{array}$ & $\begin{array}{l}\text { - surface debris } \\
\text { - electronic shorts } \\
\text { - low productivity }\end{array}$ \\
\hline
\end{tabular}

\section{Method}

In this paper, a process for lessening the thermal effect of laser ablation of a FPCB (Flexible Printed Circuit Board) is introduced. To ablate a FPCB, a pico-second laser (Super RAPID: Lumera laser $\mathrm{GmbH}$ ) and a nano-second laser (Q302-HD: JDSU) are utilized. 
Table 2 shows the experimental conditions with variable parameters including the wavelength, pulse duration, repetition rate, scanning speed and average power. The pico-second laser is a compact, diode-pumped $\mathrm{Nd}: \mathrm{YVO}_{4}$ laser. Its pico-second pulses have high peak power, easily reaching peak power densities in the $\mathrm{TW} / \mathrm{cm}^{2}$ range. Thus, it was believed that this laser can minimize the thermal effect associated with the ablation of polymers.

The main experimental results were the distribution of chemical compositions and melts on the cut edge to clarify the thermal effect. In this study, the cut edge was observed by SEM and weight percentage of ingredients was measured using EDX.

Table 2 Comparison between the punching and laser cutting processes of a FPCB

\begin{tabular}{|c|c|c|c|c|}
\hline $\begin{array}{l}\text { Vari- } \\
\text { ables }\end{array}$ & $\begin{array}{l}\text { Sym- } \\
\text { bols } \\
\text { /unit }\end{array}$ & \multicolumn{2}{|c|}{$\begin{array}{l}\text { Ps-laser } \\
\text { (Lumera) }\end{array}$} & $\begin{array}{c}\text { Ns-laser } \\
\text { (JDSU) }\end{array}$ \\
\hline $\begin{array}{l}\text { Wave- } \\
\text { length }\end{array}$ & $\lambda / \mathrm{nm}$ & 532 & 355 & 355 \\
\hline Spot size & $\phi / \mu \mathrm{m}$ & \multicolumn{3}{|c|}{30} \\
\hline $\begin{array}{l}\text { Focal } \\
\text { length }\end{array}$ & $\mathrm{F} / \mathrm{mm}$ & \multicolumn{2}{|c|}{100} & 100 \\
\hline $\begin{array}{l}\text { Rayleigh } \\
\text { length }\end{array}$ & $\mathrm{L} / \mathrm{mm}$ & \multicolumn{3}{|c|}{$2(\mathrm{~L}=\pi(\phi / 2) 2 / \lambda)$} \\
\hline $\begin{array}{l}\text { Pulse du- } \\
\text { ration }\end{array}$ & $\mathrm{D}_{\mathrm{p}} / \mathrm{sec}$ & \multicolumn{2}{|c|}{$12 \times 10^{-12}$} & $80 \times 10^{-9}$ \\
\hline $\begin{array}{l}\text { Repeti- } \\
\text { tion rate }\end{array}$ & $\begin{array}{l}\mathrm{REP} / \\
\mathrm{kHz} .\end{array}$ & \multicolumn{2}{|c|}{100} & 30 \\
\hline $\begin{array}{l}\text { Scan } \\
\text { speed }\end{array}$ & $\begin{array}{l}\mathrm{V} / \\
\mathrm{mm} / \mathrm{sec}\end{array}$ & $\begin{array}{c}20- \\
2000\end{array}$ & $\begin{array}{l}30 \\
300\end{array}$ & $250-2000$ \\
\hline $\begin{array}{l}\text { Total in- } \\
\text { put en- } \\
\text { ergy }\end{array}$ & $\begin{array}{l}\mathrm{E}_{\mathrm{in}} / \\
\mathrm{J} / \mathrm{mm}\end{array}$ & $\begin{array}{c}0.35- \\
0.6\end{array}$ & 0.2 & 0.2 \\
\hline
\end{tabular}

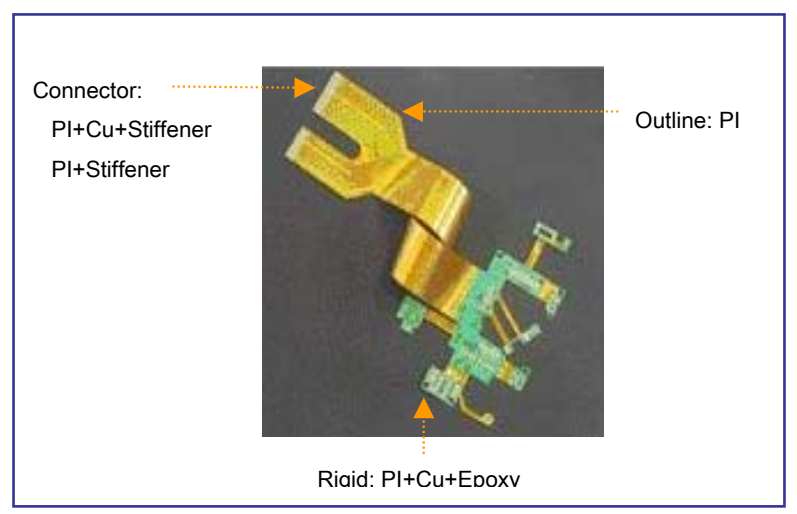

Fig. 1. Fabricated FPCB sample

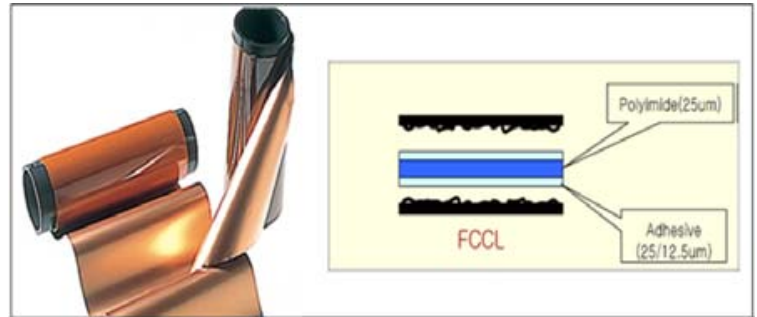

Fig. 2. Picture and structure of FCCL (Flexible Copper Clad Laminate)

Figure 1 shows a fabricated FPCB sample consisting of a connector, a rigid part and a flexible part. This FPCB is primarily made of polyimide, copper and a stiffener. Thus, the experimental material was formulated into polyimide and FCCL (Flexible Copper Clad Laminate) in the form of polyimide film and a copper foil in three layers, as shown in Fig. 2.

\section{Results and Discussions}

\subsection{Comparison of input energy and process time}

The absorption range of polyimide has an upward curve from $360 \mathrm{~nm}$ to the VUV range, while the absorption peak of copper is located in the range of wavelengths below 600 $\mathrm{nm}[1,11]$. Thus, 355nm and 532nm laser beam has different absorption mechanism on cutting FPCB.

Figure 3 shows graphs for a comparison of the input energy and cutting time by the pico-second laser beam whose wavelengths are $355 \mathrm{~nm}$ and $532 \mathrm{~nm}$ under the picosecond pulse duration. As different average powers are used, each wavelength has a different ablation threshold of the material. That is, a $532 \mathrm{~nm}$ wavelength pico-second laser beam cannot cut FCCL with an average power of 0.6 $\mathrm{W}$, whereas a $355 \mathrm{~nm}$ wavelength pico-second can easily cut FCCL. Thus, the cutting characteristics were compared using the input energy and cutting time instead of the average power. The total input energy per unit length $\left(E_{i n}\right)$ can be defined by Eq. (1); the total input energy unit length is a multiplication of the pulse energy ( $\mathrm{P}_{\mathrm{ave}} / \mathrm{Rep}$.), the pulse unit length (Rep./V), and the number of cycles (N)

In this experiment, the $532 \mathrm{~nm}$ pico-second laser beam required approximately two times the input energy per unit length in comparison with the $355 \mathrm{~nm}$ laser beam. However, the cutting time decreased drastically when using laser beam $532 \mathrm{~nm}$ pico-second laser beam. This indicates that a $532 \mathrm{~nm}$ pico-second laser can overcome laser beam low absorption issue compared to the $355 \mathrm{~nm}$ laser beam, thus increasing productivity.

$$
E_{\text {in }}=\frac{P_{\text {ave }}}{\text { Rep. }} \times \frac{\text { Rep. }}{V} \times N=\frac{P_{\text {ave }}}{V} N
$$




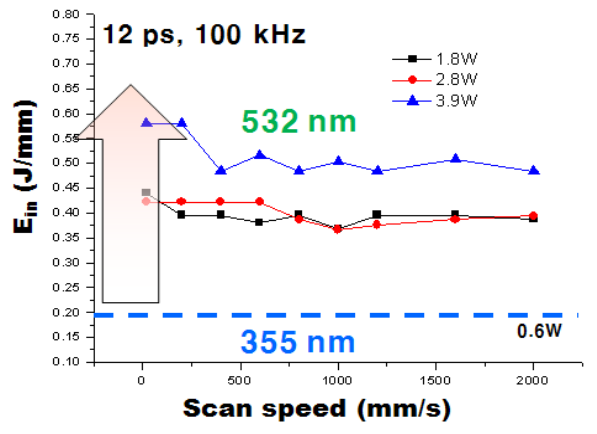

(a)

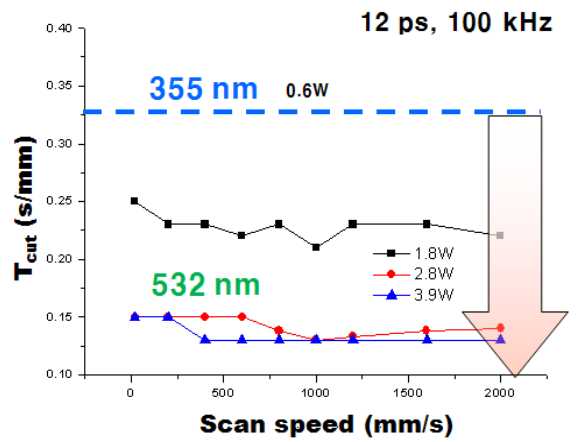

(b)

Fig. 3. Comparison of (a) the input energy and (b) the process time between the $355 \mathrm{~nm}$ ps-laser and the $532 \mathrm{~nm}$ pslaser

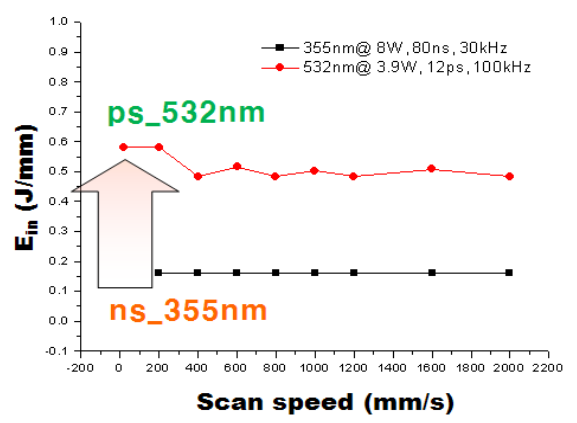

(a)

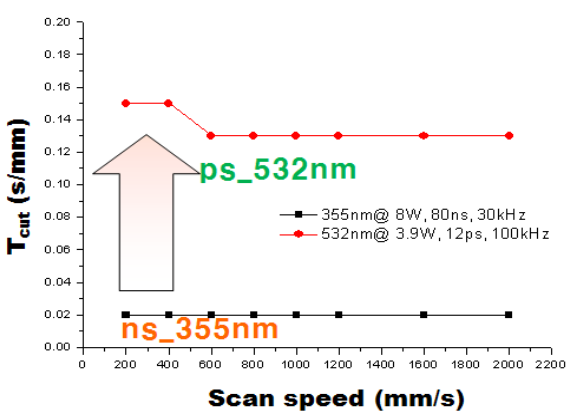

(b)

Fig. 4. Comparison of (a) the input energy and (b) the process time between the $355 \mathrm{~nm}$ ns-laser and the $532 \mathrm{~nm}$ pslaser

Figure 4 shows graphs of a comparison of the input energy and cutting time between the $532 \mathrm{~nm}$ pico-second and the $355 \mathrm{~nm}$ nano-second laser beams. For the $532 \mathrm{~nm}$ picosecond laser cutting test, the input energy per unit length and the cutting time have higher values compared to those for the $355 \mathrm{~nm}$ nano-second laser. That is, the $532 \mathrm{~nm}$ picosecond laser beam required three times the input energy and seven times the cutting time. This indicates that 532 $\mathrm{nm}$ pico-second laser beam show lower productivity in comparison with the $355 \mathrm{~nm}$ nano-second laser beam at each power.

However, for $532 \mathrm{~nm}$ pico-second laser, the melt on the cut edge was decreased drastically in comparison with the 355 nm nano-second laser. Figure 5 shows SEM images of the cut edge of the FCCL after both the $532 \mathrm{~nm}$ picosecond laser and the $355 \mathrm{~nm}$ nano-second laser were used. As illustrated in Fig. 5, the $532 \mathrm{~nm}$ pico-second laser beam has a smooth cut edge whereas the $355 \mathrm{~nm}$ nano-second laser leaves a considerable amount of melt on the cut edge. It is therefore concluded that the $532 \mathrm{~nm}$ pico-second laser is a more feasible choice for clean cutting.

\subsection{Analysis of electronic resistance and chemical compositions}

For the purpose of more intensive study, the electronic resistance and chemical compositions between copper layers were analyzed with an increase of the repetition rate and cutting speed. Figure 6 shows a weight percentage comparison of the copper in the polyimide layer of the FCCL with an increase of the repetition rate between lowspeed and high-speed processes. For the weight percentage of copper, the low-speed $(30 \mathrm{~mm} / \mathrm{s})$ process showed a higher quantity of copper and lower electronic resistance in comparison with the high-speed process $(300 \mathrm{~mm} / \mathrm{s})$. From Fig. 6(b), the electronic resistance and weight percentage of the copper increase as the repetition rate increases. In particular, the weight percentage of carbon and oxygen under the con-ditions of a cutting speed $300 \mathrm{~mm} / \mathrm{s}$ and a repetition rate $100 \mathrm{kHz}$ are similar to those values for unablated polyi-mide, which originally contains carbon at $71.6 \%$ and oxygen at $20.7 \%$. This indicates that the high-speed process and a high peak power with a low repetition rate can reduce the copper content on the insulation layer and prevent electronic short circuits.

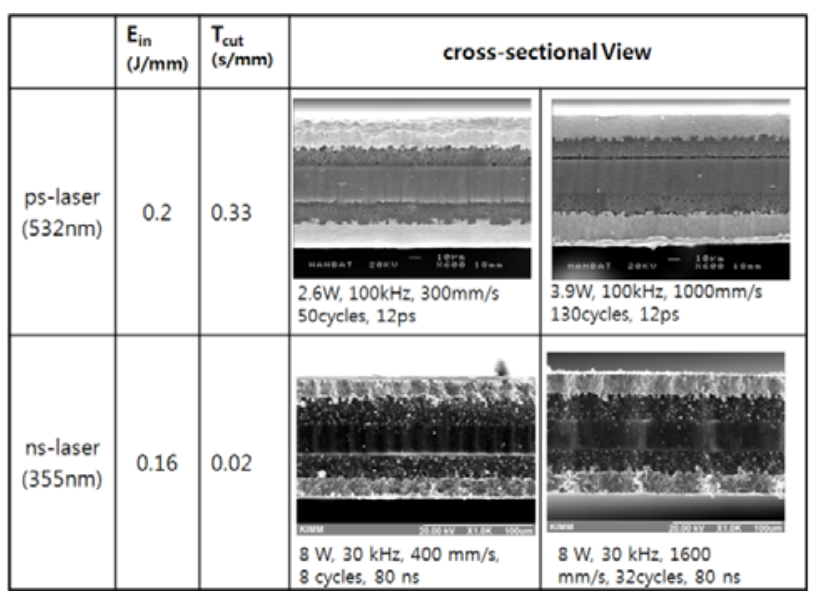

Fig. 5. SEM images of the cut edge of FCCL using a 532 $\mathrm{nm}$ ps-laser and a $355 \mathrm{~nm}$ ns-laser 


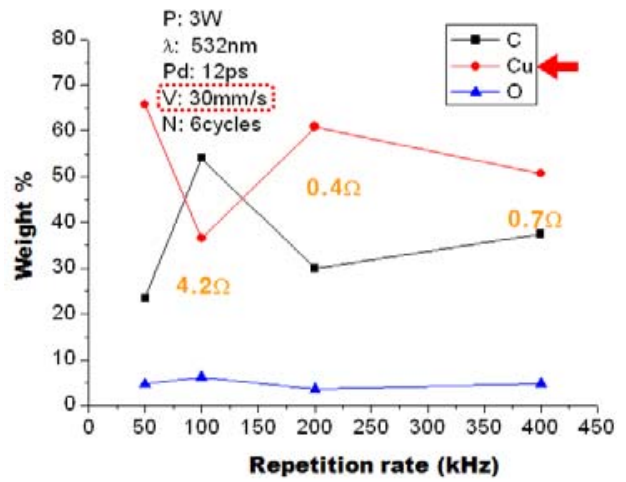

(a)

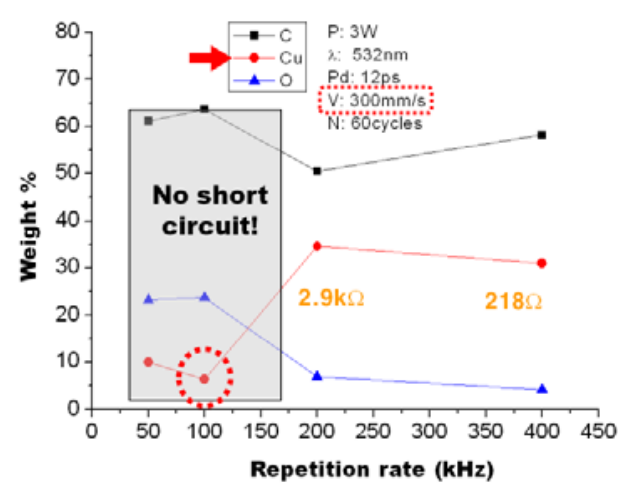

(b)

Fig. 6. Comparison of weight percentages of copper in the polyimide layer of FCCL after (a) low-speed 30 $\mathrm{mm} / \mathrm{s}$ and (b) high-speed $300 \mathrm{~mm} / \mathrm{s}$ cutting

In order to clarify the effect of the scan speed, the chemical content between the copper layers of FCCL were analyzed. Figure 7 shows the weight percentage of copper and SEM images in polyimide with an increase of the scan speed under the same input energy $\left(\mathrm{E}_{\mathrm{in}}: 0.58 \mathrm{~J} / \mathrm{mm}, \mathrm{P}_{\text {ave }}\right.$ : $3.9 \mathrm{~W}$, Rep: $100 \mathrm{kHz}$ ). The weight percentage of copper decreased from $70 \%$ to $10 \%$ between a scan speed 200 $\mathrm{mm} / \mathrm{s}$ and $400 \mathrm{~mm} / \mathrm{s}$ and reached its lowest level at 1000 $\mathrm{mm} / \mathrm{s}$. However, the highest speed induced steady growth of the copper percentage. The SEM images at the highest speed can explain the steady growth of the copper percentage. The images show that copper-based particles are stuck on the groove of the cut edge. Hence, an optimum cutting speed of $1000 \mathrm{~mm} / \mathrm{s}$ is necessary to prevent electronic short circuits.
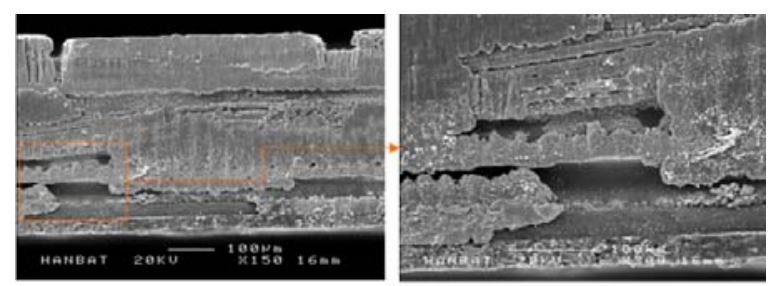

(a)
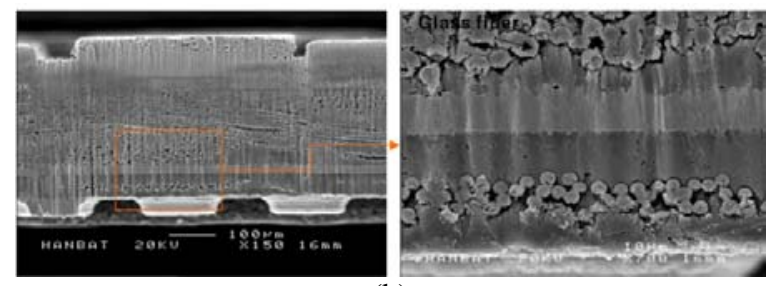

(b)

Fig. 8. SEM images of the cut edge of a rigid layer of a FPCB under the following conditions: (a) ns-laser: $80 \mathrm{~ns}, 355 \mathrm{~nm}, 30 \mathrm{kHz}, 8 \mathrm{~W}, 1600 \mathrm{~mm} / \mathrm{s}, 300$ cycles and (b) ps-laser: 12 ps, 532 nm, $100 \mathrm{kHz}, 3.8$ $\mathrm{W}, 1000 \mathrm{~mm} / \mathrm{s}, 1700$ cycles

Figure 8 shows SEM images of the cut edge of a rigid layer which has various layers that include glass fiber, polyimide, epoxy and copper. For the cutting process, laser beams are utilized under the following conditions: nanosecond laser ( 80 ns, 355 nm, 30 kHz, 8 W, 1600 mm/s, 300 cycles) and pico-second laser (12 ps, $532 \mathrm{~nm}, 100 \mathrm{kHz}, 3.8$ W, $1000 \mathrm{~mm} / \mathrm{s}$ ). A comparison between Fig. 8(a) and Fig. 8(b) makes a distinction between the thermal effect of the nano-second laser and that of the pico-second laser. That is, the pico-second laser beam can cut the rigid part of a FPCB precisely with less thermal effect such as melting whereas a nano-second laser beam shows much more of a thermal effect.
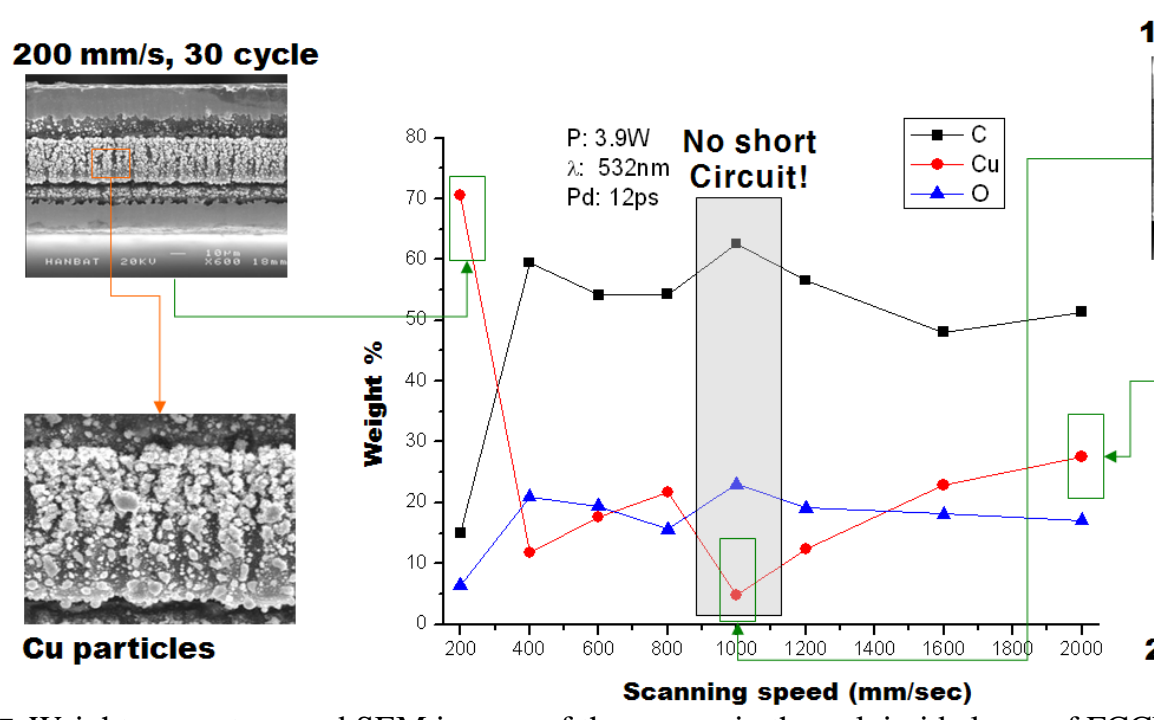

$1000 \mathrm{~mm} / \mathrm{s}, 150$ cycles
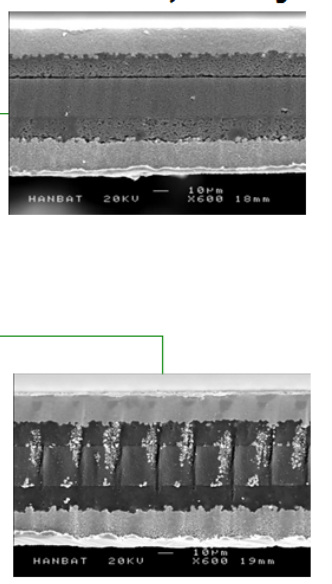

$2000 \mathrm{~mm} / \mathrm{s}, 250$ cycles

Fig. 7. Weight percentage and SEM images of the copper in the polyimide layer of FCCL according to the cutting speed 


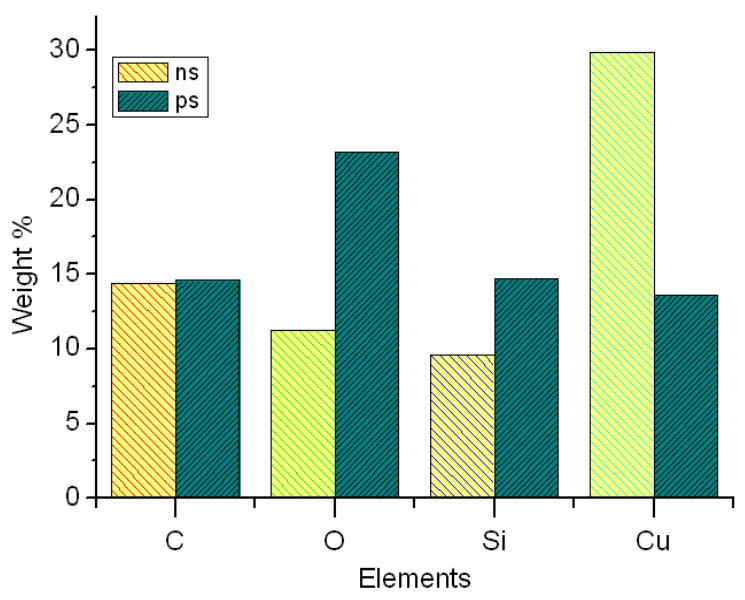

Fig. 9. Comparison of EDX analysis results pertaining to the dotted line in Fig. 8 between ns-laser and pslaser cutting

Figure 9 shows the EDX analysis results of the glass fiber layer after cutting using the nano-second laser and the pico-second laser. The glass fiber layer primarily contains silicon and oxygen elements. The edge cut by the picosecond laser is distinguished from that cut by the nanosecond laser. That is, an edge cut by the pico-second laser beam contains chemical composition that is similar to those in the glass fiber which is the base materials on measured area, whereas an edge cut by the nano-second laser beam contains different elements, such as higher cop-per and lower silicon oxide percentages. It indicates that nanosecond laser beam can contaminate cut-edge with melted copper on cutting FPCB and this contamination can be an origin of electronic shorting.

\section{Conclusions}

A multi-cycled high-speed laser process can reduce the thermal effects on FCCL. The thermal effects, melting, electronic shorting and coarse cut edges decreased as the peak power and cutting speed increased. A pico-second laser beam can cut a FPCB precisely with less thermal effect while a nano-second laser beam shows much more of a thermal effect. However, one additional limitation remains in the cutting of FPCBs precisely using a laser. This limitation is a low level of mass productivity, as a pico-second laser cannot radiate a high-power ultraviolet laser beam above $2 \mathrm{~W}\left(\mathrm{P}_{\mathrm{ave}}\right)$. To offset this limitation, a high-power nano-second UV laser is recommended. Although the nanosecond laser can induce greater thermal effects as compared with a pico-second laser, a multi-cycled high-speed process can likely minimize the thermal effects of the nanosecond laser. This will be discussed in a separate paper.

\section{Acknowledgments}

This work was supported by the Korean Ministry of Knowledge Economy within the project "Development of Precision-Machining Technology using Advanced Lasers."

\section{References}

[1] Matt Henry, Paul Harrison, Jozef Wendland, Ducan Parsons-Karavassilis: in proceedings of ICALEO 2005, 412.

[2] Schmidt, M., Eber, G.: in Proceedings of ICALEO 2003, 123.

[3] Owen: "LIA Handbook of Laser Materials Processing”, by Magnolia Publishing Inc, (2001), p. 661.

[4] Meier, D.J. and Schmidt, S.H.: CircuiTree, (2002) ADD-2-1-5.

[5] N. Arnold and N. Bityurin: Appl. Phys. A, 68, (1999), 615.

[6] G.C. D'Couto and S.V. Babu: J. Appl. Phys., 76, (1994), 3052.

[7] S.R. Cain, F.C. Burns, C.E. Otis and B. Braren: J. Appl. Phys. 72, (1993), 5172.

[8] N. Arnold, B. Luk'yanchuk and N. Bityurin: Appl. Surf. Sci., 127, (1998), 184.

[9] D.S. Shin, J.H. Lee, Y.W. Chung, J. Suh and H.K. Sohn, "Laser Cutting Process for FPCB," Smart Manufacturing Application, ICSMA, (2008), 357.

[10] D.S. Shin, J.H. Lee, Y.W. Chung, J. Suh and H.K. Sohn,"UV Laser Processes for FPCB Cutting," ICALEO (2007), 360.

[11] J.H. Brannon, J.R. Lankard, A.I. Baise, F. Burns and J. Kaufman: Journal of Applied Physics, 58(5), 1985, 2036-2043.

(Received: July 10, 2009, Accepted: January 13, 2010) 